\title{
O TRABALHO DE CAMPO E O ENSINO DE GEOGRAFIA ${ }^{1}$
}

\author{
Davis Gruber Sansolo
}

O trabalho de campo esteve presente como uma atividade de fundamental importância para a Geografia desde os viajantes da Antigüidade, passando pelos naturalistas e os organizadores da Geografia Moderna (DREYEREIMBKE, 1992; MENDOZA et alii, 1982).

Essa atividade vem percorrendo os caminhos da Geografia sem que a maioria dos autores busque um aprofundamento do debate teórico sobre as técnicas propriamente ditas e o método a que estão vinculadas. De forma geral este tema tem passado pela tangente nas discussōes sobre a metodologia científica em geral. As técnicas propriamente ditas são abordadas sob aspectos relativos aos procedimentos de execução. Raramente são analisadas sob os aspectos ideológicos e, portanto, epistemológicos, dos procedimentos adotados.

Dificilmente encontramos trabalhos que vinculem uma técnica especifica ao objetivo social do trabalho. Uma exceção é o material apresentado por OLIVEIRA (1985) em que sào apresentados dois textos específicos sobre o trabaIho de campo: "Pesquisa e Trabalho de Campo" (LACOSTE, 1977) e "O Geógrafo e a Pesquisa de Campo" (KAISER, s/d).

Destacamos também o ensaio sobre a natureza do trabalho de campo em Geografia de SILVA (1982) no qual classifica três modalidades: trabalhos analíticos empiricos, trabalhos com enfoque lógico e a análise dialética epistemológica e ontológica.

Ao longo da história do pensamento geo- gráfico, encontramos nas correntes determinista e possibilista, como procedimentos metodológicos, um empirismo reflexivo ou analítico (MENDOZA et alii, 1982).

O trabalho de campo foi o meio pelo qual construiu-se a base do conhecimento geográfico. E mesmo junto ao movimento de renovação da Geografia, ou seja, na Geografia Pragmática ou Sistêmica (TRICART, s/d) e na Geografia Crítica, não foram dispensadas as práticas de observação de campo, apesar das técnicas cibernéticas, do sensoriamento remoto e outras técnicas disponíveis (SILVA, 1982).

Contudo, uma reflexāo contemporānea sobre a importância e o vinculo que essa atividade possui com as diversas concepçōes pedagógicas é extremamente escassa, e mais ainda quanto ao ensino de Geografia e Educação Ambiental, tendo em vista que essa prática sempre é revalorizada, desde as primeiras séries até a terceiro grau.

Apoiamo-nos em autores de diversas concepções sobre a importància do trabalho de campo, desde concepçóes associadas a uma prática de ensino descritiva, cujo vínculo está presente na Geografia Clássica e cuja contribuição, em nosso entender, está associada às descriçōes extremamente precisas das evidèncias das paisagens, até autores ligados ao movimento da Geografia Crítica, que através da análise das contradiçōes sociais procuram estabelecer uma leitura dialética da aparência dos fenômenos expressos no espaço geográfico. 
Não pretendemos ser ecléticos ao buscar apoio em autores de diferentes e muitas vezes divergentes concepçōes ideológicas. Ao contrário, ao longo do trabalho esperamos que fique evidente nossa posiçāo quanto aos objetivos políticos de nosso trabalho. Entretanto, entendemos que não podemos simplesmente descartar o conhecimento já acumulado. Podemos sim recolocá-lo segundo nossas necessidades.

Não é porque o avião tenha sido aprimorado para finalidades militares que hoje deixamos de utilizá-lo para viagens. Assim como o sensoriamento remoto, a informática e diversos outros avanços científicos e tecnológicos, originalmente desenvolvidos com finalidades militares e portanto para atender às necessidades do Estado e de quem dele se beneficia de forma privilegiada, podemos trabalhar com técnicas e metodologias que originalmente estavam vinculadas a outras orientações ideológicas.

Segundo TRICART (s/d) "(...) devemos justificar o lugar que o campo ocupa no desenvolvimento do conhecimento, o que nos leva a definir uma posição metodológica"

Tendo definido nossa intenção de sermos recursivos quanto ao conhecimento acumulado, passamos então a detalhar nossa posição quanto ao trabalho de campo no ensino.

LACOSTE (1985) afirma que "para a maioria dos estudantes, a experiência da pesquisa se limita a este exercicio suplementar de reprodução de conhecimentos já elaborados sem que tenham tomado consciència das possibilidades que teriam de produzir, por si mesmos, elementos de um novo saber"

Freqüentemente os trabalhos de campo, sejam eles elaborados por bacharéis ou por professores com suas turmas escolares, dão pouca importância para as populações que foram estudadas.

Sobre o trabalho de campo, é uma atividade que possibilita uma leitura de parte da realidade a qual desejamos compreender, ou seja, a aparéncia, o fenómeno que expressa parte da esséncia desta realidade: a parte que podemos ver, ouvir, cheirar, tocar, dimensionar. No entanto, náo nos dá a possibilidade de atingir a complexidade da totalidade da realidade, dando sim, pistas as quais poderemos seguir por caminhos que permitem um aprofundamento no fenômeno e através das quais poderemos chegar à essència da realidade.

Conforme LEFEBVRE (1995), "a matéria só tem cor diante de nossos olhos; só tem odor para o nosso nariz. Ela não é a cor ou o odor. Nào obstante, a matéria é a coisa que tem a propriedade de produzir a cor e o odor em sua relação com o real conosco"

Entretanto o autor argumenta que ao chegarmos à essència, estaremos diante de parte dela, resultante de uma reflexão, de uma forma de pensar sobre ela; diante do movimento que indica o devir (id., ibid.). Portanto, entendemos o trabalho de campo como parte de um processo de busca do conhecimento, em que nos relacionamos com o fenômeno segundo nossas próprias experiências.

Considerando o presente trabalho voltado principalmente ao educador, a ênfase de nossas preocupaçōes sobre o trabalho de campo tem como prioridade a sua função pedagógica, numa perspectiva de que o processo de ensino-aprendizagem deva se dar mediado pela construção do conhecimento.

Portanto, entendemos que associadas às diversas formas que a sociedade compreende a construção do conhecimento estão as diferentes concepções de trabalho de campo.

Conforme nossos objetivos pedagógicos subdividimos em duas modalidades os trabalhos de campo: "Excursões Geográficas" (CARVALHO, 1941) e o "Trabalho de Campo para a Pesquisa Geográfica"

\section{A excursão geográfica}

Esta tem sido a modalidade mais comum no ensino de Geografia e mesmo na Educação Ambiental. Caracteriza-se pelos aspectos ilustrativos, em que a observação empirica é a téc- 
nica principal utilizada, sendo na maioria das vezes direcionada pelo educador que a priori já possui conhecimentos gerais e específicos do trajeto a ser observado, portanto já conhece o fenômeno e impóe um ponto de vista segundo suas observaçōes e reflexōes.

O lado lúdico e os relatórios valorizados por notas para avaliação são os principais incentivos para a participaçāo dos educandos, além é claro da sociabilidade proporcionada pela atividade (CARVALHO, 1941).

Segundo CARVALHO (1941) "o contato com a realidade determina por si só o início de todo um processo de aprendizagem" Em nosso entender esta afirmação indica que esta modalidade está relacionada com a ciência positivista, em que o conhecimento é dado pela observaçáo e descriçāo das evidèncias da paisagem.

Segundo CHALMERS (1990),

"Os positivistas visavam mostrar que a ciència autêntica é verificada e mostra ser verdadeira ou provavelmente verdadeira em relação a sentenças protocolares fatos revelados a observadores cuidadosos por meio de seus sentidos"

Dessa forma, esta modalidade carrega em si uma conotação ilustrativa do conhecimento, assim como mapas e livros didáticos que simplesmente ilustram o conhecimento depositado pelo professor. O inverso, ou seja, um conteúdo que esteja sendo desenvolvido em sala de aula, também poderá ser ilustrado com uma excursão geográfica, onde, então, ao longo do percurso o professor orientará a observaçáo sobre os diversos elementos discutidos e analisados em sala de aula, portanto com uma teorização prévia.

Nessas excursóes o educando participa principalmente através das habilidades sensoriais, para apreender uma parte da realidade enfocada, tendo uma postura que poderiamos classificar de relação entre sujeito e objeto de conhecimento.

Eventualmente, baseado em teorizações e apresentaçōes prévias de informações sobre a realidade a ser visitada, o professor propõe um certo controle das informaçōes antecipadamente apresentadas. Contudo, normalmente essas informaçōes acabam por tornar-se também ilus trações de verdades previamente estabelecidas e o aprendizado é avaliado pela quantificação estabelecida.

Souza SANTOS (1988) argumenta que,

"Em primeiro lugar conhecer significa quantificar. O rigor científico afere-se pelo rigor das mediçōes. As qualidades intrinsecas do objeto são, por assim dizer, desqualificadas e em seu lugar passam a imperar as quantidades em que eventualmente se podem traduzir. O que não é quantificável é cientificamente irrelevante. Em segundo lugar, o método cientifico assenta na redução da complexidade"

Por outro lado, eventualmente quando uma turma excursiona para um determinado local visando a observação da paisagem "natural" o professor sugere atençāo para um determinado fenòmeno ou elemento da natureza, solicitando aos alunos que se utilizem da visão para uma descriçāo do observado. Quando isso acontece, é um grande avanço em relação à maioria das excursões, em que o professor se adianta aos alunos, fazendo ele as observaçōes e descriçōes da paisagem, retirando do aluno a oportunidade do exercício de observação e descrição (CARVALHO, 1941). Como resultado, temos registros ou relatórios que expressam as observaçōes e pontos de vistas do professor. As interpretaçóes, muitas vezes são feitas na própria excursão e elaboradas em cima das observações do educador, portanto nāo sāo construídas pelos alunos, transformando-se em uma atividade meramente ilustrativa.

A excursāo geográfica possui sua devida importância nos vários estágios do desenvolvimento do processo de ensino-aprendizagem. Nas séries iniciais pode assumir um papel importante no desenvolvimento de habilidades de observação e descriçāo, raciocínio indutivo e deduti- 
vo e relaçōes interpessoais e até mesmo na organização e registro de conhecimentos. Tais habilidades serão de grande valia, principalmente a partir do final do ensino fundamental (de $5^{\mathrm{a}} \mathrm{s}$ a $8{ }^{\text {a }}$ s séries) e no ensino médio, onde a pesquisa geográfica deverá ser produzida.

Quanto à prática da excursāo geográfica CARVALHO (1941) chama atenção para o planejamento dessa atividade, que, segundo ele, envolve cinco fases: a) preparo preliminar; b) preparo psicológico; c) organizaçāo da excursão; d) observação dirigida; e) os relatórios.

\section{Trabalho de campo na pesquisa geográfica}

Nào obstante a existência de diversas concepçóes e linhas de pesquisa e de desenvolvimento pedagógico, a pesquisa geográfica é enfocada aqui como um processo pedagógico de produção de conhecimento científico de forma participante (VIANA, 1986; BRANDÃO, 1981; GAJARDO, 1986). Sendo geográfica, portanto com suas especificidades, busca a construção acerca de um ou mais temas referentes ao espaço geográfico, consequentemente procura a essência das relaçóes que se estabelecem e que se expressam através de fenômenos, da aparência do espaço, de uma paisagem, temas relativos ao meio físico ou aos fatores sociais que envolvem a produção e organização do espaço.

Conforme LACOSTE (1985):

"Mesmo pesquisas que apenas recaem sobre os caracteres físicos de um território nāo deixam, por isso, de dizer menos respeito à população que aí vive, na medida em que seus resultados tornam mais eficaz uma intervenção aí"

PONTUSCHKA (1994) desenvolve o conceito de Estudo do Meio a partir da escola, através da prática interdisciplinar, objetivando-se o desenvolvimento de valores e habilidades, que possibilitem ao educando pensar e agir em sua realidade espacial sem esquecer, é claro, que essa realidade está inserida em um contexto, cuja natureza é presente com suas formas e processos únicos em cada realidade, seja a natureza próxima de seu estado original ou mesmo em seu estado alterado pelo trabalho e pela cultura humana.

O conceito de meio, segundo Coimbra (1985), refere-se à superfície ou volume em que se insere um ponto qualquer, indicando a noção espacial em seu sentido geométrico. O que está dentro ou inserido está, portanto, no meio, mas sem limites definidos. "Na realidade concreta das várias situações, cada ser que está em um meio qualquer, por sua referência, é o centro desse meio" (Id., ibid.).

Esta é uma das formas (espaço geométrico) de se encarar o espaço geográfico, e já fora criticada por diversos geógrafos (por exemplo, LACOSTE, 1977), pois o lugar enfocado de forma estanque e desarticulada de outros níveis espaciais nos remete à concepçāo de regiào lablachiana, que esconde as determinações sociais ou mesmo conflitos e interesses que muitas vezes ocorrem ou somente podem ser entendidos em outras escalas, diferentes da local. O meio, como indicado, infere uma escala e é claro que não pode ser ignorado, pois ali é que se materializam as relaçōes sociais. Este lugar, além de social, também é material, pois sua natureza obedece leis gerais e assume particularidades locais, segundo suas próprias caracteristicas e segundo a interferência da sociedade.

Portanto, a compreensão dos processos naturais, em nosso entender, é de fundamental importância para a compreensão da dimensão ambiental no espaço geográfico.

COLTRINARI (1993) afirma que devemos ter uma postura científica perante as questòes ambientais, mais especificamente quanto às mudanças globais, uma vez que vários conceitos estão sendo divulgados sem a devida relativização referente ao tempo-espaço, levando-se em conta as diversas escalas nas quais ocorrem os processos da natureza, de diversas intensidades.

Essas questões nos levam a pensar que as escolas possuem um papel de responsabilida- 
de quanto à produção de conhecimento, através de pequenas pesquisas, que possibilitem aos educandos uma postura crítica e criativa diante da realidade vivenciada pelos próprios produtores do conhecimento. A desmitificação de conceitos poderia ser uma das prioridades, ao contrário de práticas muito comuns, como a repetição de jargōes do tipo "Amazônia pulmão do mundo" ou mesmo a afirmação de conceitos sobre aspectos da natureza que nem ao menos foram sentidos ou vivenciados, como a relação entre os diversos tipos de materiais e a variação de temperatura ${ }^{2}$

Portanto, o ensino através da pesquisa geográfica, aqui, é enfocado como processo de produção do conhecimento geográfico (RESENDE, 1989), ou seja, de uma leitura elaborada pelos próprios educandos. Leitura esta voltada à construção de valores necessários à promoção da cidadania e mais especificamente à gestão do espaço geográfico e do meio ambiente de forma participativa.

Essa modalidade de trabalho de campo caracteriza-se como combinação da modalidade de pesquisa propriamente dita e a de finalidade didática ${ }^{3}$

Diferente da excursão geográfica, entendemos essa modalidade como parte de uma metodologia de pesquisa, sendo fundamental procedimento para o processo de construçāo de conhecimento.

Será nesta atividade, dentro de um projeto de pesquisa, que educador e educandos utilizarão, além da percepção, um instrumental técnico capaz de auxiliá-los no principal objetivo do trabalho de campo: a observação ${ }^{4}$ (JUNKER, $1971)$.

A observação e a utilização de técnicas de mensuraçāo e coleta de dados servirāo para buscar na realidade concreta algumas informaçóes (sobre os fenômenos) que indicarão pistas (através de símbolos), que levarão à compreensão das articulações com outras escalas geográficas que, relacionadas às características locais, concretizam o espaço geográfico e, portanto, as condiçōes do meio ambiente local, produzidas ao longo do tempo histórico e do tempo da natureza, em diferentes escalas temporais e espaciais.

Assim, quando observamos processos de degradação da natureza, como poluição das águas, ocorrência de distúrbios em vertentes, como deslizamentos e outros movimentos de massa, poluiçāo do ar e outras formas de degradação, estas estarão evidenciadas na paisagem, ou seja, nas escalas locais e regionais. Contudo, não poderão ser explicadas se tratadas exclusivamente nessas escalas, uma vez que tais processos decorrem de decisões que muitas vezes estão distantes do local.

“(..) a sociedade não pode ser percebida como simplesmente dada, ela é construída. (...) náo podemos nos colocar como meros consta-tadores da sociedade, mas saber sermos seus próprios sujeitos constitutivos $e$ construtivos. Nesta perspectiva, a realidade local deve fazer parte do currículo escolar, enquanto objeto de indagação, reflexão e trabalho" (SÃO PAULO, 1990).

Tratando-se de trabalho de campo voltado à pesquisa sobre o espaço geográfico, e mais especificamente ao meio ambiente, devemos ter clareza que estaremos com um problema de natureza metodológica, mais ainda, de trato epistemológicos, cuja abordagem é essencialmente interdisciplinar, envolvendo questōes relativas à cultura, ao cotidiano e à sociedade, assim como questóes do meio físico e biológico, utilizando, portanto, métodos e técnicas diferenciados e até contraditórios, sem que sejam essencialmente excludentes.

Somente nas formas é que poderemos observar, medir e registrar em trabalho de campo os fenómenos percebidos. Sào elas que se apresentam em um determinado momento e é esse momento que resgatamos da realidade.

Por outro lado, como percebemos, os fenómenos é que se traduzem em conhecimento, mesmo considerando uma realidade objetiva in dependente de nossa percepçào (SANTOS, 1995). 
Quanto aos procedimentos, STERNBERG (1946) afirma que, de forma simplificada, o trabalho de campo consiste em observar, descrever, registrar. Claro que, ao contextualizarmos o autor na história do pensamento geográfico, evidenciaremos um método, uma lógica, uma forma de pensar a construção do conhecimento. Porém, não invalida a importância das habilidades por ele valorizadas.

THIOLLENT (1980) analisou as críticas ao empirismo e classificou-o como uma das técnicas de observação:

"A noção de observação não deve ser considerada como sinônimo de empirismo. É preciso entender que este último é apenas uma ideologia particular de observação. Criticar as ideologias de observação, sejam elas empiriristas, positivistas ou psicologistas, não consiste em rejeitar todo o tipo de observação ou de questionamento concreto, sempre indispensável em qualquer pesquisa científica para dar conta do relato e eventualmente enriquecer a teoria"

A ida a campo deve proporcionar uma releitura ou mesmo um leitura personalizada baseada em dados concretos do real, daquilo que será pesquisado. Uma leitura feita através da percepção em um primeiro momento ${ }^{5}$ (DOWNS \& STEA, 1976). Um registro original, que terá como característica uma interação entre o perceptivel (a paisagem como um todo e seus elementos compositores) e a história de vida pessoal, relevando-se aí o cognitivo e o afetivo previamente estruturados.

Esta afirmação nos traz a uma reflexão sobre a inesgotável possibilidade que a observação humana tem de captar, sob as mais variadas perspectivas, a complexidade da realidade, em especial do meio ambiente.

Aproveitando a denominação indicada por RUELLAN (1944), classificamos o trabalho de campo para pesquisa geográfica em duas fases: A excursão de reconhecimento e a investigação minuciosa.

\section{A excursão de reconhecimento}

Entendemos esta modalidade de trabalho de campo como uma fase determinante em um processo de problematização em uma metodologia de pesquisa, especialmente quando tratamos de um projeto de pesquisa participante (FREIRE, 1981).

Nāo é do trabalho de campo que surge a problematização, mas é com os subsídios que o mesmo proporciona através da leitura da paisagem que podemos dar um contorno, uma melhor definiçáo sobre o problema que almejamos compreender e sobre o qual pretendemos agir. É no sentir a realidade que podemos objetivar nossas açōes e, portanto, retomar, redefinir os objetivos específicos em uma metodologia de pesquisa participante.

Nossas utopias são anteriormente pensadas, nossos problemas são antecipadamente relatados, entretanto, nossos critérios são definidos e redefinidos ao longo do processo, com auxílio de nossa percepção da realidade.

O reconhecimento destina-se a um primeiro contato com o local a se realizar a pesquisa, como já explicita o próprio enunciado. Caracteriza-se por ser feita em um pequeno espaço de tempo, conforme o tamanho do território, e pelo levantamento do maior número possivel de informações a serem sistematizadas, o que será proporcional à experiéncia dos pesquisadores, tanto no que se refere ao conhecimento do território propriamente dito, quanto à experiència em outros trabalhos de campo.

A disciplina voltada à aquisiçāo de informaçōes, baseada em objetivos previamente definidos, problematizaçóes preestabelecidas e calcadas em elaboraçōes teóricas, será de importãncia fundamental para a sistematização dessas percepçóes. Entretanto, devemos estar abertos a todo tipo de informaçōes que, mesmo indiretamente, serviráo como referenciais para a composiçáo de uma imagem mental sobre o território a ser reconhecido ou conhecido originalmente. 
Lee, Stea \& Blaut (apud HART e MOORE, $\mathrm{s} / \mathrm{d}$ ) afirmam que caminhar e pedalar é fundamental para crianças, pois assim estabelecem relação intima com o ambiente, ao contrário de meios passivos de locomoção. A ludicidade também é importante para uma relação com o ambiente.

Entendemos que não só para crianças a manipulação do meio, ou seja, caminhar, tocar, "sentir" um determinado local, é de fundamental importància para a formação de um conceito, mesmo que subjetivo, acerca de um território, para um futuro aprofundamento sobre as questōes do meio ambiente.

TUAN (1980), aborda as relaçóes que as pessoas desenvolvem com o meio, que podem assumir o caráter de topofilia ou topofobia, ou seja, relaçóes de prazer ou de resistència a determinados lugares. Sentimentos que são construidos a partir de vivèncias e experiências culturais e, portanto, simbólicas com o meio.

Para que um trabalho de campo se desenvolva e obtenha resultados satisfatórios, é necessário não somente uma reflexão teórica acerca de sua importància para a pesquisa, mas também um planejamento minucioso, que leve em consideraçāo um itinerário, que possibilite a observação de contrastes na paisagem.

Ao explanar sobre metodologia da pesquisa participante, FREIRE (1981) indica a necessidade do que ele chama de visita exploratória e afirma sobre esta que:

"(...) impōe-se uma delimitação da área na qual se faria pesquisa, reconhecendo-se, naturalmente que não há fronteiras rigidas em se tratando de cultura .Delimitada a área, a equipe faria as suas primeiras visitas informais, anotando tudo que lhe chamasse atençào, conversando com uns, com outros. Fundamental nestas visitas exploratórias seria a identificação de organismos populares ou oficiais como clubes de futebol, escolas públicas, clubes de dança, cooperativas etc."

RUELLAN (1944) indica que devemos "cortar acidentes essenciais do relevo de modo a poder apreender os contrastes de aspectos e as transiçōes que ela apresenta tanto do ponto de vista físico como do ponto de vista humano".

Pontos extremos são interessantes para uma observação geral, como os cumes e os fundos de vales, onde poderemos ter vários ângulos de visão. Enfim compreendemos esta modalidade como um passo fundamental para um processo de problematização inerente à metodologia de pesquisa.

Mensurações, questionários e outros procedimentos de controle e experimentação, em nosso entender, são desnecessários neste momento, em que se pretende estabelecer uma leitura preliminar que fornecerá subsidios para uma melhor definição do trabalho. Contudo, alguns procedimentos técnicos voltados à ampliação das observações e mesmo para sua posterior sistematização podem ser de grande valia, como registros em cadernetas de campo, fotografias e esboços da paisagem, além de regis tros de entrevistas e referenciais de orientação e localização.

Em uma metodologia de pesquisa participante, o trabalho de campo de reconhecimento possibilita uma redefiniçāo dos objetivos especificos, definidos previamente durante a elaboraçào do projeto de pesquisa, e por conseguinte escolher as técnicas e procedimentos adequados que auxiliem na aquisição de dados em trabalhos de campo.

\section{Trabalhos de campo para investigação minuciosa}

Tratando-se de uma metodologia participante, sobre esta fase podemos dizer que se trata do miolo do trabalho, parte cuja problemática central já foi definida ao longo do processo já tendo sido previamente reconhecido o território onde se desenrolará a pesquisa. Portanto, tratase de uma fase em que os problemas especificos serāo averiguados em campo, experimentados in loco, onde se pretende estabelecer uma aproximaçào da realidade. 
RUELLAN (1944) chama a atençāo para o fato que o trabalho de campo na pesquisa geográfica não deve ser para o reencontro do que já foi dito ou escrito por determinadas personagens, mas deve direcionar-se a "controlar cuidadosamente as observações e as interpretaçōes dos predecessores, para confirmá-las, completá-las, graduá-las ou mostrar o que têm de inexato, a fim de chegar à realização de um trabalho de conjunto original, por tudo que traz de novo sobre o assunto".

TRICART (s/d), ao discutir a função do trabalho de campo na Geografia, em especial nos procedimentos metodológicos ligados à investigação geográfica do meio físico, estabelece uma distinção entre simulação e experimentação: "simulaçāo consiste na produção de um fenômeno natural após isolá-lo de seu contexto, de maneira a melhor conhecer parte dos parametros que o comandam". O autor indica uma ausência de uma fronteira definida entre a simulação e a experimentação e afirma que: "O objetivo da experimentaçào é em princípio, controlar os efeitos esperados de tal qual modificação introduzida nas condiçōes iniciais existentes na natureza" (id., ibid.)

Há de se esclarecer que, apesar de nos colocarmos a favor e procurarmos seguir um caminho alternativo aos paradigmas da ciência moderna, não pretendemos simplesmente ignorar ou ainda manter uma oposição sistemática. Mesmo porque, na medida em que os caminhos já trilhados nos auxiliarem, não temeremos em segui-los. Entretanto, o repensar e a autocrítica serão constantes ao longo de nossas proposições.

Nesse contexto, entendemos que a observação através dos sentidos (percepção) não perde seu valor (apesar de parecer um tanto óbvio), mesmo nesta fase cuja caracteristica baseia-se em aproximaçōes da realidade através de experimentos, inquéritos ou entrevistas.

P.GEORGE (s/d), afirma que "em qualquer procedimento geográfico o primeiro passo é a observação" Contudo, esta modalidade de trabalho de campo vem cumprir o papel de levantamento de informações mais especificas, preci- sas, qualitativa e quantitativamente, demandando procedimentos técnicos mais especializados e adequados aos objetivos da pesquisa.

Sendo assim, os experimentos vêm suprir parte da necessidade de construçāo do conhecimento. Os mesmos possibilitam lançar luz sobre uma questão significativa, à qual denominamos de problemática previamente construída (CHAMLERS, 1994).

Numa defesa do experimento, o autor argumenta que "os julgamentos sobre a suficiência ou significado de um resultado experimental dependem das pressuposiçóes de maior ou menor nivel teórico a respeito da conveniência dos aparatos experimentais" (Id., ibid.). Ainda sobre o caráter da relação do experimento com a realidade, afirma que,

"Embora se possa admitir para o cético que todas as observações e seus relatórios e justificativas experimentais necessariamente sejam formulados em linguagem teórico-dependente, é importante admitir também que o experimento não implica simplesmente falar sobre o mundo, mas, na prática, agir sobre ele" (CHAMLERS, 1994).

Portanto, os resultados dos experimentos, assim como inquéritos e entrevistas, assumem significados conforme o olhar que se dá ao problema enfocado. Sobre inquéritos através de questionários, THIOLLENT (1980) apresenta uma critica a esses procedimentos quando os mesmos são produzidos segundo uma ótica da neutralidade cientifica e argumenta que:

"trata-se de pôr em foco a própria formação dos dados tal como é realizada na prática de investigação por intermédio de técnicas conhecidas, como questionários e entrevistas. Questionaremos os dados e os instrumentos que os moldam. Isto supóe que a neutralidade ou a nàoneutralidade dos mesmos estejam postas em questão desde o começo, isto é, desde a formulação do questionário ou desde a situação da entrevista" (Id., ibid.).

Enfim, não pretendemos esgotar a discussão sobre as técnicas e suas relaçóes com o método. Pretendemos chamar a atenção da im- 
portância de se refletir quando e como o trabalho de campo pode ser importante, em especial para o ensino de Geografia.

Em termos gerais, grande parte dos professores compreendem a importância de se desenvolver trabalhos de campo como uma atividade didático-pedagógica (LEAL FILHO, 1991). Entretanto, entendemos que além dos problemas estruturais ( básicos) que a escola pública possui, o maior problema é a falta de compreensão do que se quer e aonde queremos chegar com essa atividade. Mais do que isso, o que queremos com o ensino de Geografia?

Como professor de prática de ensino em Geografia, constato que os alunos no final do curso de Geografia não têm total clareza do porqué ensinar Geografia. Procuramos demonstrar a esses futuros professores (em um futuro bem próximo), que a mera crítica da realidade já não basta aos alunos da escola contemporânea. O exercício da abstração e crítica (o que náo ocorre em grande parte do ensino de Geografia) deveria avançar para a construção do conhecimento crítico sim, mas não como fim, e sim como meio de transformação, ou seja, mudança da realidade concreta.

O debate poderia se ampliar muito, por exemplo, de se questionar qual o papel da escola na sociedade contemporanea. Nesse trabalho, nos restringimos a levantar algumas reflexões de como o trabalho de campo é importante não somente para desvendar, para se alfabetizar sobre a leitura da paisagem, mas também como instrumento de mudança.

\section{Notas}

1 Msc Davis Gruber Sansolo. Separata de Dissertaçāo de Mestrado "A importância do trabalho de campo no ensino de Geografia e para a educaçāo ambiental" defendida em 1996 no Dep. de Geografia da USP.

${ }^{2}$ O Prof. Gil Sodero desenvolveu oficina sobre a relaçāo de materiais diversos com a variação de temperatura durante o "II Fala Professor". Ocorrido na USP em 1992. Nesta oficina, foram discutidas as relaçōes entre diversos materiais sob diversas condiçōes de temperatura e a relaçāo com a dinâmica climática da realidade.
3 Sobre modalidades de trabalhos de campo em Geografia ver STERNBERG, Hilgard O'Reilly (1946).

${ }^{4}$ Segundo JUNKER, "Observaçāo é a coleta de informaçōes (...), de primeira mão por uma atenção constante, com a máxima utilização das habilidades perceptivas e das sensibilidades do observador a todos acontecimentos acessiveis e relevantes (...) que se desenrolam na situação imediata de campo, durante certo período de tempo"

5 Para DOWNS \& STEA a percepçāo pode ser definida como "um processo que ocorre pela presença de objetos e que resulta por uma apreensão imediata desses objetos, por um ou mais sentidos"

\section{Bibliografia}

BRANDÃO, C.R. (Org.). Pesquisa Participante. São Paulo, Brasiliense, 1990, 221 p.CARVALHO, Delgado A Excursāo Geográfica. Revista Brasileira de Geografia, Ano 3. No.4, 1941 , pp. 95-96.

CARVALHO, M.B.. Natureza na Geografia do Ensino Médio. In: UMBELINO, A.(org.) et. alli, Para Onde Vai o Ensino de Geografia ? Sāo
Paulo, Contexto, 1989, pp. 81-108. CASTROGIOVANI, A.Carlos \& GOULART,LIGIA B.. "Uma Contribuição à Reflexão do Ensino da Geografia. A noção de Espacialidade e o Estudo da Natureza" In: Terra Livre: Geografia, Pesquisa e Prática Social. Sáo Paulo, AGB \& Marco Zero, 1990. pp. $112: 115$. 
CHAlmers, Alan. A Fabricaçāo da Ciência São Paulo, Editora da UNESP, 1994, 185 p.

COLTRINARI, Lylian. Estudos internacionais sobre mudanças globais e novos conflitos, In: SOUZA, Maria A., SANTOS, M., SCARLATO, F.C., ARROYO, M. (organizadores). O Novo Mapa do Mundo : Natureza e Sociedade de Hoje: uma leitura geográfica. Sào Paulo, HUCITEC, 1993, pp. 99-104.

DREYER-EIMBKE, Oswald. O Descobrimento da Terra História e Histórias da Aventura Cartográfica. São Paulo, Melhoramentos/ EDUSP, 1992, $260 \mathrm{p}$.

DURAND, Gilbert. A Imaginação Simbólica São Paulo, Cultrix \& EDUSP, 1988.

ESTEVAS, Joaquim (coord) et alii. Educación Popular Ambiental en América Latina, México, Red de Educacion Popular y Ecologia REPEC/CEAAL, 1994. 148 p.

FERREIRA, Edson Alberto C. Anotações sobre alguns pré-requisitos fundamentais para uma possivel unidade do conhecimento geográfico. Revista do Departamento de Geografia, $N^{\circ} 5$. São Paulo, FflCH-USP, 1991, pp. 67-72.

FERREIRA, C.C. \& SIMÓES, N.N. Evoluçāo do Pensamento Geográfico. Lisboa, Gradiva, 1986, $142 \mathrm{p}$.

FREIRE, Paulo. Pedagogia do Oprimido. Rio de Janeiro, Paz e Terra, 1987184 p.

Criando Métodos de Pesquisa Alternativa : aprendendo a fazê-la melhor através da ação. In: BRANDĀO, C.B (Org.), Pesquisa Participante. São Paulo, Brasiliense, 1990, Pp.32-62.

FREIRE, Paulo \& RIVERE, Pichon. O Processo Educativo. Petrópolis, Vozes, 1989.

GAJARDO, Marcela. Pesquisa Participante na América Latina. São Paulo, Brasiliense, 1986, $94 \mathrm{p}$.

GEORGE, Pierre. Os Métodos da Geografia São Paulo, Difusāo Européia do Livro, s.d., Pp. 19-4l.

GONÇAlvES, Carlos Walter Porto. Possibilidades e Limites da Ciência e da Técnica Diante da Questão Ambiental. GEOSUL. Revista do Departamento de Geociéncias - $\mathrm{CCH}$ da Universidade Federal de Santa Catarina, $N^{\circ} 5$ - Ano 3 Florianópolis, Editora da UFSC, 1988, pp. 7-40.

GOULD, Peter \& WHITE, Rodney. Mental Maps. Otawa, Pelican Books, Pelican Geography and Enviromental Studies, (mimeo), s/d, $203 \mathrm{p}$.

HARPER, B. ett alli. Cuidado Escola. $35^{\mathrm{a}}$ ed. São Paulo, Brasiliense, 1994, 118 p.

HART, A.R. \& MOORE T.G- The Development of Spatial Cognition: A Reviw (s.n.t.)( Mimeo).

JUNKER, Buford H. A Importância do Trabalho de Campo: Introdução às Ciências Sociais. Rio de Janeiro, Ed. Lidador, 1971 , 214 p.

LACOSTE, Yves. A Geografia Serve Antes de Mais Mada Para Fazer a Guerra. Lisboa, Iniciativas Editoriais, 1977

Pesquisa e trabalho de Campo. Seleção de Textos-Teoria e Método, $\mathrm{N}^{\circ} 11$, Sāo Paulo, AGB, 1985, pp.1-23.

Os Objetos Geográficos. Seleção de Textos-Cartografia temática, $\mathrm{N}^{\circ} 18$, São Paulo, AGB, 1988, pp 1-23.

LEAL FILHO, W.D.S.. Estudo de Campo nas escolas brasileiras. Revista Ciência Hoje, V.13 $N^{\circ}$ 78. Sāo Paulo, Sociedade Brasileira Para o Progresso da Ciência, 1991.

LEITE, Maria Angela F. P.. Destruição ou Desconstruçāo? Questões da paisagem e tendências de regionalização. Sāo Paulo Hucitec / FAPESP, 1994, 117p.

LEFEBVRE, Henri. Lógica Formal / Lógica Dialética. $6^{a}$ ed. Rio de Janeiro. Civilização Brasileira. 1995, $301 \mathrm{p}$.

MARQUES, L.S. \& MARQUES, T.E. Estudo do Meio: Estudos Sociais para o meio rural. Porto Alegre, Mercado Aberto, s/d, $70 \mathrm{p}$.

MENDOZA, Josefina Gomes, JIMENEZ, M. Julio, CANTERo, N. Ortega. El Pensamiento Geográfico Madrid, Alianza Editorial, 1982. $529 \mathrm{p}$.

NILDELCOFF, M.T. A Escola e a Compreensão da Realidade. Sāo Paulo, Brasiliense, 1980. 
OLIVEIRA, A.U.. Na prática a teoria é outra para na prática não pode e não Deve Ser Outra, In:

PONTUSCHKA, Nídia Nacib. A Formaçāo Pedagógica do Professor de Geografia e as Práticas Interdisciplinares. Tese (doutorado) Sāo Paulo, Faculdade de Educaçào da Universidade de Sào Paulo, 1994, 343 p.

RUELLAN, Francis. O Trabalho de Campo nas Pesquisas Originais de Geografia Regional. In: Revista Brasileira de Geografia, ano IV, $\mathrm{N}^{\circ} 1$. Rio de Janeiro, IBGE, 1944.

SÃO PAULO (Município). Relatos de Práticas Pedagógicas: Gestão Colegiada na Escola, uma aula de cidadania. São Paulo, Secretaria Municipal de Educação, 1992, 36 p.

SÃO PAULO (Municipio). Um primeiro olhar sobre o projeto. Cadernos de Formação. Série: Ação Pedagógica da Escola Pela Via da Interdisciplinariedade. São Paulo, Secretaria Municipal de Educação, Diretoria de Orientação Técnica, Núcleos de Ação Educativa e Acessoria da Universidade de São Paulo, Pontifícia Universidade Católica de São Paulo, UNICAMP e educadores das escolas-piloto, 1992, 58p.

SÃO PAULO (Município) Estudo Preliminar da Realidade Local: resgatando o cotidiano. Cadernos de Formação, $\mathrm{N}^{\circ} 2$ Sào Paulo, Sec.Municipal Educação, 1990, 62 p.

SANTOS, Boaventura de Souza. Um Discurso sobre as Cièncias na Transição para uma Ciència Pós-Moderna. Estudos Avançados, Vol. 2 No. 2, São Paulo, Universidade de São Paulo, 1988 pp. 46-71.

SANTOS, Douglas. Conteúdo e Objetivo Pedagógico no Ensino da Geografia. Geografia e Ensino Caderno Prudentino de Geografia, $N^{\circ} 17$. Presidente Prudente, AGB-Seção Presidente Prudente, 1995, pp. 20-61.

SANTOS, Milton. Por Uma Geografia Nova. Sāo Paulo, Hucitec-EDUSP, 1978, 236 p.

O Trabalho do Geógrafo no Terceiro Mundo. São Paulo, Hucitec, 1979, 113 p.

Espaço e Método. $3^{a}$ ed. Sāo Paulo, Nobel, 1992.
SEVERINO, Antonio Joaquim. Da escola como mediação necessária do necessário projeto educacional, In: Subsidios Para Os Encontros Regionais para o XIV Congresso Estadual de Educação. São Paulo, APEOESP, 1995, p.p 3:4.

SILVA, Armando Corrẽa. Natureza do trabalho de campo em Geografia Humana e suas limitações, Revista do Departamento de Geografia, $\mathrm{N}^{0} \mathrm{l}$, São Paulo, Faculdade de Filosofia, Letras e Ciências Humanas, 1982, pp. 49-54.

SIlva, Maria Ozanira da Silva e. Pesquisa Paticipante. São Paulo, Cortez, 1986, $174 \mathrm{p}$.

STERNBERG, O.H.. Contribuiçāo ao Estudo da Geografia: o trabalho de campo na Geografia e o Laboratório de Geografia e o equipamento didático. Rio de Janeiro, Ministério da Educação e Saúde Serviço de Documentação, 1946.

THIOLLENT, M. Critica Metodológica: Investigação social e enquete operária. São Paulo, Pólis, 1980.

TRICART, Jean. Ecodināmica Recursos Naturais e Meio Ambiente, No.1 Rio de Janeiro, IBGE, Diretoria Técnica, SUPREN, 1977 $97 \mathrm{p}$.

Paisagem e Ecologia, (Texto provisório). Trad. Monteiro, C.A.F. (Mimeo.), São Paulo, 1981.

O Campo na Dialética da Geografia. Reflexóes sobre a Geografia, (Mimeo.), São Paulo, AGB S/D.

TUAN,Yi-fu. Topofilia, Um Estudo da Percepção, Atitudes e Valores do Meio Ambiente. São Paulo, Difel 1980, 288 p.

Espaço e Lugar : A perspectiva da Experiência Trad. Livia de Oliveira. São Paulo Difel, 1983, 250 p.

VIANNA, Ilca Oliveira de Almeida. Planejamento Participativo na Escola: um desafio ao educador. Sào Paulo, Ed. Pedagógica e Universitária 1986, 118 p. 